\title{
Learning from Rare Events: An Analysis of ValuJet Flight 592 and Swissair Flight SR 111 Crashes
}

\author{
Konstantinos Grigoriou, Ashraf Labib*, Sara Hadleigh-Dunn \\ University of Portsmouth, UK
}

E-mail addresses:

konstantinos.grigoriou@myport.ac.uk (K. Grigoriou )

ashraf.labib@port.ac.uk (A. Labib)

sara.hadleigh-dunn@port.ac.uk (S. Hadleigh-Dunn)

*Corresponding author: Ashraf Labib

\begin{abstract}
:
Why do organisations need to learn from prior failures in this uncertain and complex environment? How can they learn from prior failures? This paper aims to answer the above questions using the relevant literature and by analysing two cases from the aviation industry. To achieve this, Fault Tree Analyses and Reliability Block Diagram will be applied to ValuJet Flight 592 and Swissair Flight SR111 crashes to identify their root causes and discuss the lessons learned or not learned. Thus, learning from failures using advanced techniques do not only indicates the root causes of the disaster but increase the knowledge of the organisation as they can identify the gaps in their system and learn from them.
\end{abstract}

Keywords: Learning from Rare Events, Fault Tree Analysis, Reliability Block Diagrams, ValuJet Flight 592, Swissair Flight SR 111

\section{$\underline{\text { 1. Introduction }}$}

Common sense suggests that failure is something bad and must be avoided, as failure challenge organisations, their people, functions and processes unusual. Mirvis and Berg (1977) argued that "especially in organisations, failure is often simply not tolerated, and people avoid being associated with failure of any kind". However, researchers also found that learning from prior failures is more effective than successes (Madsen \& Desai, 2010). 
Nevertheless, it can be noticed that the lessons gained from previous failures have not been learnt as the same disasters are keeping occurred by the same companies (E.g. BP Texas City, and Deep Water Horizon), within the same industry (E.g. Chernobyl and Fukushima in nuclear power plants). This paper aims to examine whether and how organisations learn from major failures. A critical literature review will give a better understanding of what is organisational learning, why it is more effective to learn from prior failures than successes and the unlearning process. Moreover, two cases from the aviation industry, ValuJet Flight 592 and Swissair Flight SR 111, will be analysed using the framework of learning from failures proposed by Labib and Read (2013) and the use of two engineering failure analysis techniques; Fault Tree Analysis (FTA) and Reliability Block Diagrams (RBD).

Considering that there are several reliability engineering-based tools and techniques, the justification for using FTA and RBD is three-fold; i) the FTA is used for problem structuring for identifying root cause analysis, whereas the RBD is used as a problem solving technique to identify the vulnerabilities within the system, ii) they are compatible to one another, where the FTA is a pre-requisite to the RBD, and hence can be used in an integrated approach, and iii) both the FTA and RND have been used as a way of demonstrating hybrid modelling for engineering failure analysis, for example: (Yunusa-Kaltungo etal, 2017), (Stephen and Labib, 2018), (Labib and Read, 2013), and (Labib and Read, 2015).

The paper is constructed as follows; section two is dedicated to literature review. Section three provides the theoretical framework and case studies using the proposed analytical tools and techniques. Finally section four prvide a discussion and conclusion.

\section{Literature Review}

The literature review section is constructed as follows; we divided it into two main subsections; on organisational learning, and learning from success or failure. The latter subsection is further divided into learning from success, learning from failure, and learning from engineering failures analysis

\section{$\underline{\text { 2.1 Organisational learning }}$}

Nowadays, it is very important that both individuals and organisations must learn systematically and rigorously from their own or other's experiences in order to adapt rapidly and continuously to their changing environments (Senge, 2006). The concept of organisational learning is rooted in many aspects of management and its practices acknowledge a broad range of factors by specifying the learning results (Garratt, 1999, p.203). The organisational learning can be considered as a tool for business success where it 
is widely accepted that it is a necessary strategy for the survival and the development of the organisation (Beer et al., 2005).

However, there is an interesting dilemma for the organisational learning as there are limited theories and models which are acceptable. During the years, scholars have referred to learning as; new systems, new structures, new insights or knowledge, or mere actions (Chandler, 1962; Miles \& Cameron, 1982; Argyris \& Schön, 1978; Cyert \& March, 1963). More recently, Madsen and Desai (2010, p.453) defined the organizational learning as "any modification of an organization's knowledge occurring as a result of its experience". Any changes in the organisational knowledge are difficult to be observed, but the empirical literature of the organisational learning suggests that changes in observable organisational performance reflect changes in organisational knowledge (Baum \& Ingram, 1998; Argote, 1999).

Organisational learning theory pointing the importance of knowledge storage and knowledge development in organisations by including the knowledge-based theory of the company, evolutionary economics and theory on organisational memory, shared cognition and group learning (Kogut \& Zander, 1996; Grant, 1996; Stalk et al., 1992). Therefore, learning from the organisation's extreme performance such as success or failure experiences had increased the attention of scholars and organisations itself (Baum \& Dahlin, 2007; Greve, 2003; Miner et al., 1996).

\subsection{Learning from success or failure:}

Although empirical literature emphasizes learning from success (McGrath, 1999; Kim \& Miner, 2000), recent scholars began to explore organisational learning from failure experience (Kim \& Miner, 2007; Desai, 2008; Madsen \& Desai, 2010). Audia and Goncalo (2007) and Baum and Dahlin (2007) found that successful experiences leading organisations to search for minor performance improvements while failure experiences drive organisations 
to search for new ideas beyond their boundaries. Louis and Sutton (1991) claimed that the unexpected events stimulate increased sense-making efforts, intensify the attribution process and enhance the process of hypothesis testing.

\subsubsection{Learning from success}

Failures are different from successes not only from the number of errors that drive to performance outcome but also because failure events are treated as opposed to successes. This can be proved by the behavioural theory of the company, which shows that the response of the organisational decision makers on failure is different from success (Madsen \& Desai, 2010). Decision makers of an organisation construe experience from success as evidence that there is no need for any further development of organisational knowledge as the existing knowledge of the organisation represents the world well (March \& Shapira, 1992; Lant, 1992; Louis \& Sutton, 1991). Thus, the organisational decision makers tend to simplify their approaches to decision-making and fail to receive information about the outside world when learning from prior successes (Hayward et al., 2004; Audia et al., 2000).

\subsubsection{Learning from failure}

On the other hand, as an event of success tends to stabilize the organisation's knowledge, failure challenges it. Failures challenge the old assumptions and status quo, motivates the organisational members to innovate and correct problems (Sitkin, 1992; Cyert \& March, 1963) and force organisational members to engage in deep or mindful reflections on what is wrong and why to represents better the reality (Weick \& Roberts, 1993; Morris \& Moore, 2000). Moreover, failure events not only indicate a gap in the knowledge of the organisation but also in many cases provides a clear identification of the roots of that gap (Turner, 1976; Levinthal \& March 1981). Experiences from failure have been related to increased risk seeking, the same as success experiences have been related to increased risk aversion (Sitkin, 1992). The ability of the organisation to take risks and admit to failure and learn from it are the keys to achieve high performance and sustainability (Sitkin \& Pablo, 1992; Peters et al., 1982). 


\subsubsection{Learning from Engineering Failures Analysis}

Learning from engineering failure analysis has been investigated by a large body of literature in the journal of Engineering Failure Analysis. Ahmad etal (2012) investigated a case study of multiple failures modes of a machinery component. Chemweno etal (2016) proposed a root cause analysis methodology for selection of maintenance strategy. Gharahasanlou etal (2014) used fault tree analysis for a crushing plant and mixing bed hall. Martinez etal (2018) performed failure analysis of subsidence in a power plant. Mesic and Plavsic (2013) analysed failures of transmission network maintenance preferential. Mulenga etal (2018) investigated root cause analysis of asbestos cement pipes case study. Murugan and Ramasamy (2015) performed failure analysis of power transformers. Yunusa-Kaltungo etal (2017) investigated critical failures using root cause analysis techniques such as fault tree analysis and reliability block diagrams for a case study in a cement company.

\subsection{The unlearning process}

However, Qi et al. (2012) in their article 'Challenges and needs for process safety in the new millennium' argued that similar incidents are occurring on a regular basis. This happens due to the lack of understanding of urgency to search for better practices which lead to organisations improvements. Qi et al. (2012) suggested three key reasons why organisations do not learn from prior failures. Firstly, the organisations have no memory and they must focus more on the past by performing root cause analysis of near misses, investigations and estimate the probabilities of major failures occurrences. Second, the organisations ignore the red flags and do not focus on the leading indicators of the disaster. The last challenge is the lack of communication between the organisation's employees and management and the increasing complexity of process operations.

Major failures, by their definition, are rare events of severe consequences. They are therefore usually 'black swans', a term coined by Taleb (2005), or an 'out-of-the-blue' event as argued by as argued by Komljenovice etal $(2017,2016)$, who proposed that they also occur due to an unlearning process that may be due to: a) unknown-unknowns (incidents that are completely unknown to the scientific community), b) unknown-knowns (analysts and those involved in the incident do not possess knowledge about a related issue but others do), and c) failure modes that are on the list of known risk, but judged as 'acceptable'). 
It is clear from the above-mentioned literature in both sections related to organisational learning, and learning from success and failure, that the majority of the literature tends to be conceptual with limited empirical, case study, oriented research. In this paper we contribute to this gap by demonstrating the incorporation of the same hybrid techniques in two case studies and identify their utility by way of illustration.

\section{Theoretical framework and case studies}

In this paper two cases from the aviation industry, ValuJet Flight 592 and Swissair Flight SR 111, were chosen to demonstrate learning from failure using the proposed framework of Labib and Read (2013) which consists of a) feedback from the users to design (ie changing the status quo), b) incorporation of engineering failure analysis tools, and c) the fostering of interdisciplinary approaches and extraction of generic lessons learnt. The Fault Tree Analysis (FTA) and the Reliability Block Diagram (RBD) will be used here to analyse the cases by developing a hybrid model in order to increase the richness of the analyses. By using a single model to analyse a problem can be inadequate to provide a realistic and an effective approach to represent complex realities, as the people who investigate the accident try to 'fit it' into the model (Kletz, 2001). The FTA will be used to identify the causal factors of both cases by distinguishing the direct and indirect causes of each event and how interacted together. Labib and Read (2015) argued that the above process of categorising the direct and indirect causes of a disaster is very useful when analysing cases in aviation, so the two cases have been chosen to support this argument.

\section{$\underline{\text { 3.1 Case } 1 \text { - ValuJet Flight } 592}$}

\subsubsection{What happened}

On May 11, 1996, a Douglas DC-9-32 operated by ValuJet Airline, Inc., as Flight 592 scheduled to depart from Miami International Airport, Florida, to Hartsfield International Airport, Georgia, carrying 110 people on board and 4,109 pounds of cargo (baggage, mail and company-owned material (COMAT)). The Flight 592 departed from Miami at 14:04:24, 
where shortly after the take off an unidentified sound recorded in the cockpit's voice recorder. At 14:10:20, the captain shouted, "We're losing everything" and requested emergency landing as an unexpected fire broke out from the airplane's cargo, causing heavy electrical problems (NTSB, 1997). Finally, at 14:13:12, ValuJet Flight 592 crashed into the Everglades coast in Florida.

\subsubsection{Logic and Technical cause of the failure}

An unexpected fire in the aircraft's class D cargo compartment was the main cause of the Flight 592 accident. Over 100 expired chemical oxygen generators were loaded into the aircraft improperly as cargo by ValuJet's maintenance subcontractor (SubreTech). The fire resulted from the actuation of one or more oxygen generators (see fig. 1) and propagated from

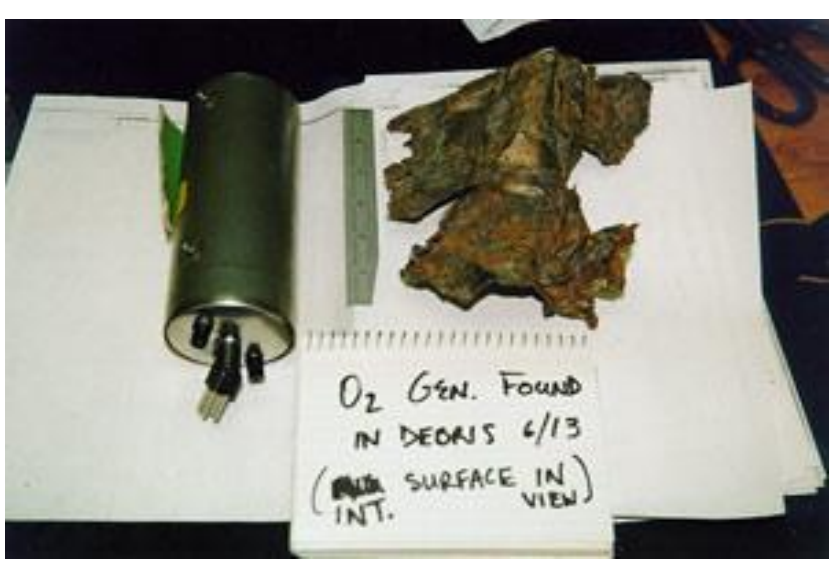

Fig. 1. NSTB photo of recovered chemical other flammable materials in the cargo (NTSB, 1997). The fire caused heavy electrical problems to the airplane's systems, hence the pilots were unable to control it.

According to the final investigation report produced by the National Transportation Safety Board (1997), there are several causes were contributed to the accident of the airplane.

a) The failure of ValuJet's maintenance subcontractor to prepare, package and identify the unexpected chemical generator before presenting them for carriage. 
b) The failure of ValuJet to oversee its maintenance subcontractor in order to ensure compliance with maintenance training and hazardous materials practices and requirements.

c) The Federal Aviation Administration (FAA) failed to require fire suppression and smoke detection systems in class D cargo compartments.

d) The FAA failed to respond to prior similar incidents.

e) The FAA failed to oversee ValuJet's responsibilities and maintenance programs.

f) The failure of ValuJet to ensure that both ValuJet and its contract maintenance employees were aware of the 'no-carry' hazardous materials policy and had the appropriate training in terms of hazardous materials.

\subsubsection{The consequences of the failure}

The crash of Flight 592 caused the death of 110 people, 5 crew members and 105 passengers, and the cost of $\$ 14$ million for recovery and clean-up operations (NTSB, 1997). Moreover, the accident caused reputational damage to SabreTech and ValuJet as Sabretech ceased operations and ValuJet bought out by AirTran.

\subsubsection{FTA and RBD for ValuJet Flight 592 crash}

The FTA is a top-down approach which shows the relationship of the system's failure. On the top of the tree is the undesirable event (Top event) followed by failures of the components of the system, called basic events of the tree. The choice of relation between factors is depicted in the choice of logic connectors in the FTA ie OR / AND gates. The AND-gates and OR-gates connect the causes of the Top event. Moreover, AND-gates show that the system configuration is in 'parallel', and OR-gates show that the system is in 'series' structure. Such 
combination of parallel and series structures are then mapped into the subsequent equivalent Reliability Block Diagram (RBD) model. The FTA shown in Figure (2) shows the direct and indirect causes of the Flight 592 crash resulted from the unexpected fire. Firstly, the usage of the AND-gate shows that both direct and indirect causes have contributed simultaneously to the incident. The occurrence of any of the events, 1 or 2 , will be resulted to the failure of the maintenance side to comply with hazardous materials, hence the reasoning behind the ORgate. The lack of supervision, poor safety culture and lack of communication had a direct impact on the incident as the management failed to oversee the maintenance operations, safety and knowledge. Also, the occurrence of the events 6 and 7 contributed to the poor design of the aircraft which failed to detect and extinguish the fire immediately. In terms of the indirect causes, the FAA failed to respond to prior similar incidents and failed to monitor ValuJet's maintenance and responsibilities. Finally, Valujet's and SubreTech's employees failed to comply with the hazardous materials policy. Please note that the expert input sought here is based on published reports. We argue that this is a reasonable assumption as we rely on credible sources. 


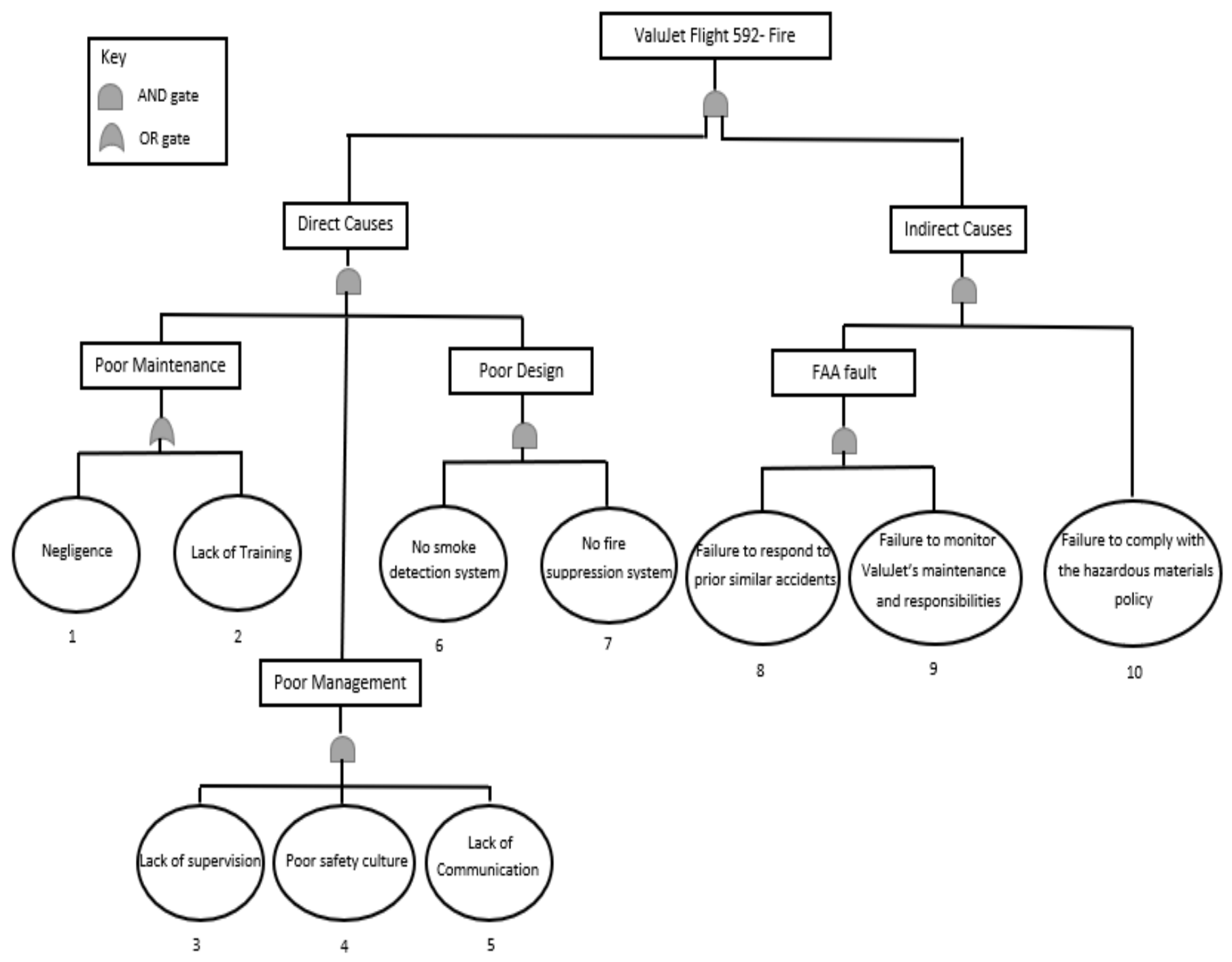

Fig. 2. FTA of ValuJet Flight 592 crash-fire

Moreover, all the information from the FTA used as an input to the RBD shown in Fig. (3) where the AND-gate on the top of the tree shows its parallel structure. The RBD makes the analyses more valuable as it highlights vulnerabilities in the whole system and hence indicates to decision makers on what events one should focus on to improve the resilience of the system. The decision makers must decrease the number of the series events to maximise the system's reliability and minimise the system's failure rate. From the RBD, it can be 
noticed that the maintenance fault it is the main cause of worry as the event 1 and 2 form a series.

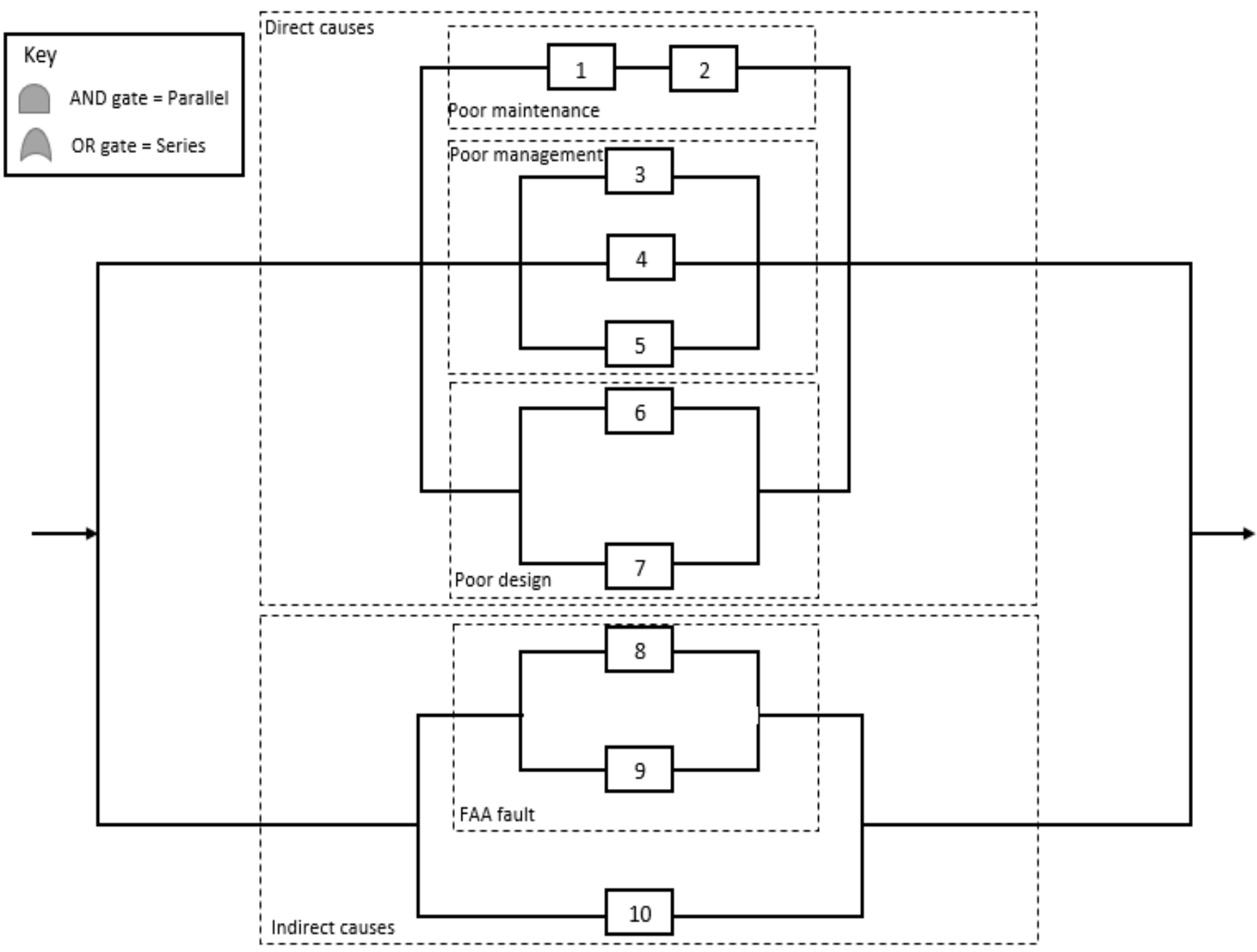

Fig. 3. RBD of ValuJet Flight 592 crash-fire

\subsubsection{Proposed improvements and generic lessons}

From the above analyses, it can be noticed that there is a need to address some important points to prevent similar incidents in the future. Firstly, there is a need for smoke detectors 
and fire suppression systems in the cargo hold. This will help to detect and extinguish the fire immediately, hence the flight crew will have valuable time to land the plane safely. Also, the airline companies must enhance and evaluate their oversight techniques in order to avoid improper maintenance activities, such as false entries. Finally, the FAA must require airline companies to ensure that their maintenance stuff, including shipping, mechanics, receiving and subcontractors are fully trained for the recognition, packaging and shipment of hazardous materials.

\subsection{Case 2-Swissair Flight SR 111}

\subsubsection{What happened}

At 00:18 on 2 of September 1998, a Douglas MD-11 operated by Swissair Airline as SR 111 departed from Jamaica International Airport, New York, to Geneva, Switzerland, carrying 229 people on board. At 01:10:38, an unusual smell and smoke detected in the cockpit but ignored from the pilots as they assumed that it is related to the air conditioning system (TSB, 2001). Four minutes later the smoke increased, and the captain requested an emergency landing to the closest airport. The pilots named Boston airport but several minutes later they preferred to land in Halifax airport which was closer, loosing valuable time. At 01:24:53, several minutes before landing, the captain started to dump fuel to avoid any further fire or explosions as some fire was visible above the cockpit. Three minutes later, the control of the aircraft lost as the fire caused heavy electrical problems and the captain declared an emergency. Finally, at 01:31:18, the flight SR 111 crashed into the Atlantic Ocean southwest of Halifax International Airport (TSB, 2001). 


\subsubsection{Logic and Technical cause of the failure}

The main cause of the Flight SR 111 crash was a fire above the ceiling of the cockpit resulted from an arcing in the wiring of the airplane's entertainment network which propagated by flammable materials (see fig. 4). The flammable materials contributed to the rapid spread of the fire causing heavy problems to the aircraft's systems, hence led to the failure to control the aircraft.

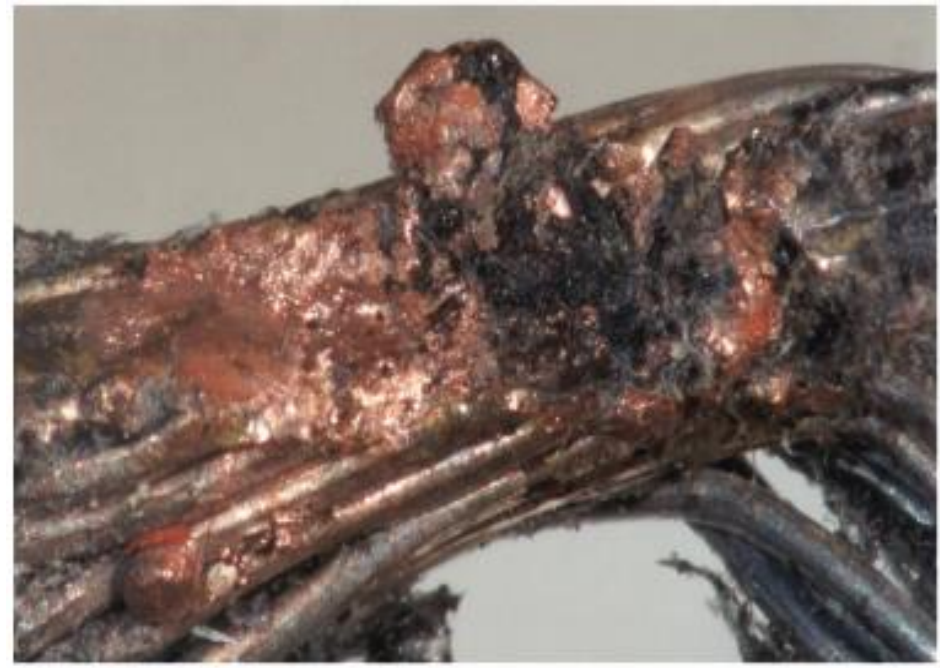

Fig. 4. The probable wire which caused the spark

According to the final investigation report produced by the Transportation Safety Board of Canada (TSB) (2001), there are several causes of the aircraft's accident.

a) Metallized polyethylene terephthalate (MPET), silicone elastomeric and caps, hookand-loop fasteners and other materials did not meet the proposed revised flammability test criteria.

b) The types of circuit breakers (CB) used were not capable to protect against all types of wiring arcing events.

c) There were no fire suppression and smoke detection systems and policies.

d) The airplane crew did not have the required training and procedures to locate and eliminate the source of smoke.

e) Aircraft certification standards for flammable materials were inadequate, as they did not restrict the use of flammable materials.

f) There was no firefighting plan. 


\subsubsection{The consequences of the failure}

The crash of flight SR 111 caused the death of all the 229 people on board, 14 crew members and 215 passengers (TSB, 2001). Moreover, there was not any environmental damage from the aircraft's crash, but the surrounding area of the incident was closed by marine traffic due to salvage operations for 13 months.

\subsubsection{FTA and RBD for Swissair Flight SR 111 crash}

The FTA shown in Fig. (5) shows the direct and indirect causes of Flight SR 111 crash resulted from fire by an arcing in the wiring. The first direct cause of the fire was the bad design of the aircraft where the incapable circuit breaks of the wires, the use of flammable materials and the lack of safety linked with an AND-gate as occurred simultaneously. The use of flammable materials is evidenced by the event 2,3 and 4 , and the lack of safety by the event 5 and 6 . The next direct cause of the fire was the faults from the flight crew as they made wrong decisions and they did not detect and extinguish the fire. The occurrence of any of the events 8,9 or 10 would result in the failure of the flight crew to detect and extinguish the fire, hence the reasoning behind the OR-gate.

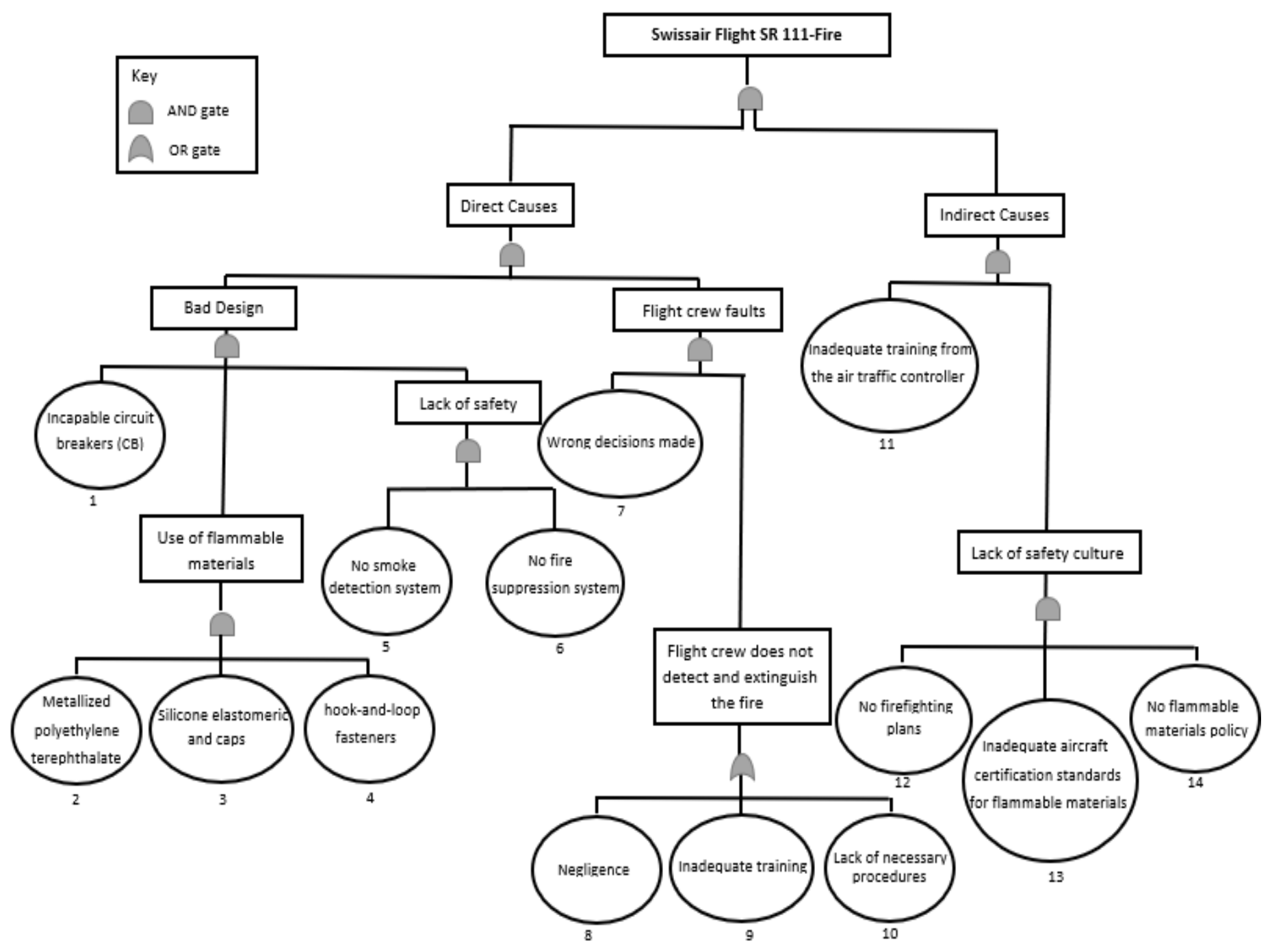


Fig. 5. FTA of Swissair Flight SR 111 crash-fire

Moreover, all the events that fall under the indirect causes occurred simultaneously, hence the usage of the AND-gate. The air traffic control had inadequate training during an emergency or abnormal situation. Also, the lack of safety culture is evidenced by the inadequate aircraft certification standards for flammable materials, no firefighting plan and no flammable materials policy. All the information from the FTA had used as an input to the RBD shown in Fig. (6) where the AND-gate on the top of the tree shows its parallel structure. From the following RBD, it can be noticed that the events 8, 9 and 10 form series configuration, so the attention must be concentrated on why the flight crew failed to detect and extinguish the fire immediately. 


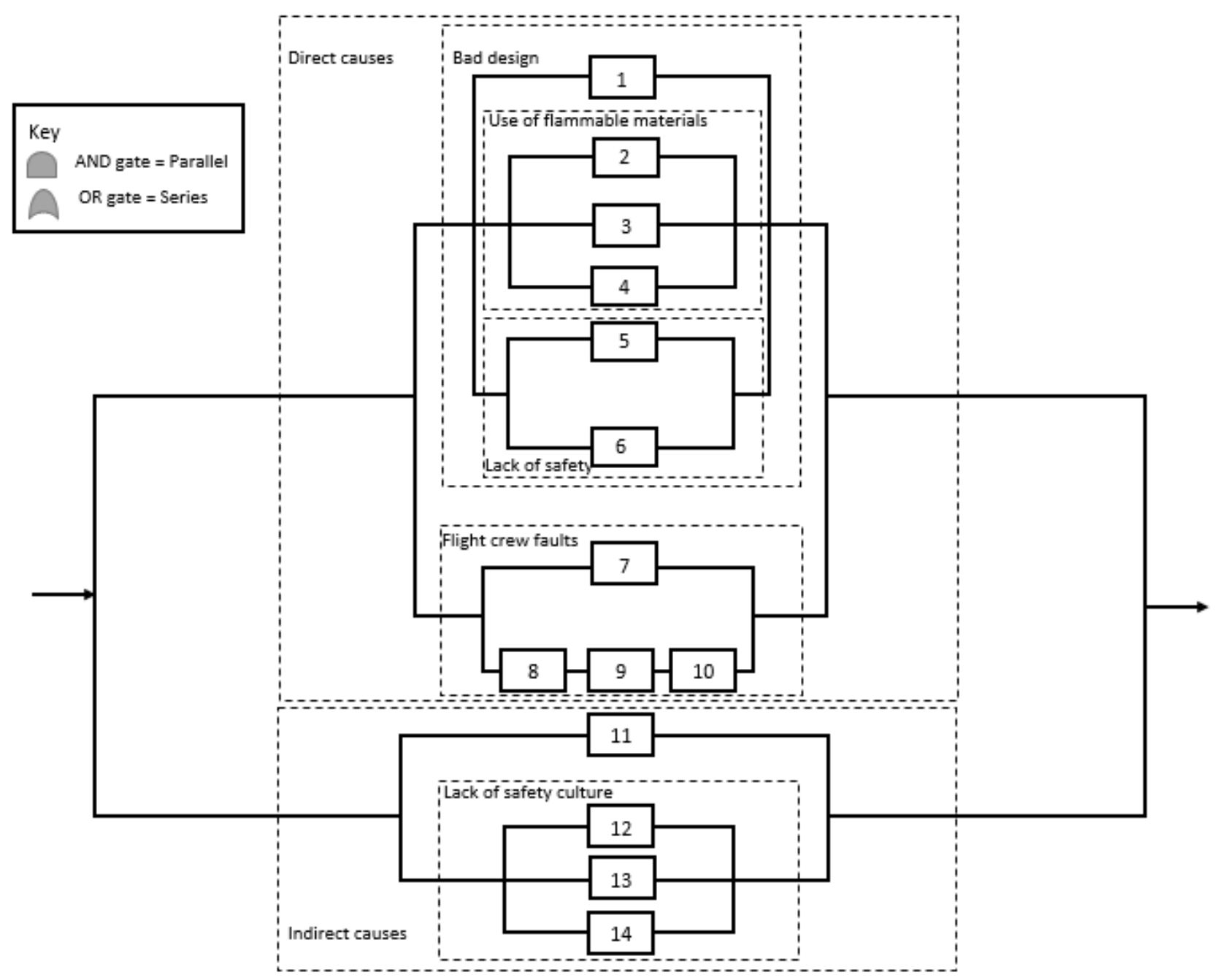

Fig. 6. RBD of Swissair Flight SR 111 crash-fire 


\subsubsection{Improvements and generic lessons}

To prevent similar incidents in the future, again there is a need for smoke detectors and fire suppression systems in the hidden areas of the airplanes, so the flight crew would be alerted to the presence of the fire. Also, there is a need of the FAA to require changes on standards, policies and regulations on airplanes wiring and flammable materials, as the aircraft certification standards for material flammability were inadequate. Moreover, the FAA must require replacing of the flammable materials, such as the metallized polyethylene terephthalate, and check the flammability of the replace materials by the necessary tests. Finally, as mentioned above there is a need to increase the knowledge of the flight crew in terms of fire and emergency situations by providing them with the necessary training and procedures, as well as with a comprehensive firefighting plan.

\section{Discussion and Conclusions}

In terms of the above analysis, the construction of the FTA and RBD helped to understand the overall system and to identify the gaps where the organisational members need to focus in order to avoid any similar incidents in the future. However, "those who cannot remember the past are condemned to repeat it" (Santayana, 1998). It is very important to note that both crashes had similar root causes with the top event the fire in the aircraft. Therefore, it can be noticed that the lessons have not been learnt as the Flight SR 111 crashed two years after the crash of Flight 592. This can be proved by the above analysis as after the accident of Flight 592 it is not clear whether the authorities and the airlines have proceeded to any changes in order to avoid similar future incidents. These changes could be 1) the better design and safety of the airplanes as smoke detection and fire suppression systems could alert the flight crew immediately and extinguish the fire, 2) more effective maintenance supervision and communication, 3) better training in terms of events of fire, emergencies and hazardous and flammable materials and 4) the authorities must require standards, policies and regulations related to the above incidents.

One however, may wonder whether by applying these methods, do they reach the same conclusions as for the original case in terms of the root causes deduced by investigators when analysing the accident cases? In response to this point, we argue that they do concur with similar conclusions derived from investigation reports, but they offer the added benefit of 
having a concise mental model that clearly summarises the root causes of the whole event from the FTA. In addition, the RBD also offers insight into the vulnerabilities of the system, which may not be explicitly captured in the investigation reports.

The main limitation of this work is that it relies on the robustness of the problem structuring phase, ie the construction of the FTA model. We constructed the FTA model based on the data available in investigation reports, but it is based on our interpretation and our background. Usually such task should be carried out by multidisciplinary teams as suggested in Labib and Harris (2015), and Labib (2014). However, the main contribution of this work is that we offer a framework for root cause analysis, and identification of vulnerabilities within the whole system.

Finally, the overall message of this paper is to understand the importance to identify the root causes of a disaster and be able to learn from it in order to ensure success and resilience of the organisations in this uncertain world. The importance of formulating a problem can be regarded as the most significant issue which was suggested many years ago by Einstein and Infield (1938) as they noted that "The formulation of a problem is often more essential than its solution, which may be merely a matter of mathematical or experimental skill". The use of both techniques, FTA and RBD, had enriched the analysis as they demonstrated how an indepth root cause analysis can provide a very useful mental model which increases the knowledge and support decisions in organisations. However, such techniques have limitations as Leveson (2004, p.240) argued that "as such, event-based models encourage limited notions of causality - usually linear causality relationships are emphasized-and it is difficult to incorporate non-linear relationships, including feedback". Nevertheless, they provide a valuable mental model that can lead to the enhancement of the resilience of systems.

Future directions of research can incorporate the use of other tools and techniques for similar types of case studies. Such techniques may include the incorporation of fuzzy logic (Yuniarto, and Labib, 2006), the analytical hierarchy process (AHP) (Labib and Shah, 2001), integer programming (Alardhi and Labib, 2008), and dominance rough set approach (DRSA) (Chakhar et al, 2016).

\section{References}

1. Alardhi, M., \& Labib, A. W. (2008). Preventive maintenance scheduling of multicogeneration plants using integer programming. Journal of the Operational Research Society, 59(4), 503-509.

2. Ahmad, R., Kamaruddin, S., Azid, I. A., \& Almanar, I. P. (2012). Failure analysis of machinery component by considering external factors and multiple failure modes-a case study in the processing industry. Engineering Failure Analysis, 25, 182-192.

3. Argote, L. (1999). Organizational learning: Creating, retaining, and transferring knowledge. Boston, MA: Kluwer Academic.

4. Argyris, C., \& Schön, D. A. (1978). Organizational Learning, Readings. MA: Addison. Chicago 
5. Audia, P., \& Goncalo, J. (2007). Past Success and Creativity over Time: A Study of Inventors in the Hard Disk Drive Industry. Management Science, 53(1), 1-15.

6. Audia, P., Locke, E., \& Smith, K. (2000). The paradox of success: An archival and a laboratory study of strategic persistence following a radical environmental change. Academy Of Management Journal, 43(5), 837-853. http://dx.doi.org/10.2307/1556413

7. Baum, J., \& Dahlin, K. (2007). Aspiration Performance and Railroads' Patterns of Learning from Train Wrecks and Crashes. Organization Science, 18(3), 368-385.

8. Baum, J., \& Dahlin, K. (2007). Aspiration Performance and Railroads' Patterns of Learning from Train Wrecks and Crashes. Organization Science, 18(3), 368-385.

9. Baum, J., \& Ingram, P. (1998). Survival-Enhancing Learning in the Manhattan Hotel Industry, 1898-1980. Management Science, 44(7), 996-1016.

10. Beer, M., Voelpel, S., Leibold, M., \& Tekie, E. (2005). Strategic Management as Organizational Learning. Long Range Planning, 38(5), 445-465.

11.Chakhar, S., Ishizaka, A., Labib, A., \& Saad, I. (2016). Dominance-based rough set approach for group decisions. European Journal of Operational Research, 251(1), 206-224.

12. Chandler, A. D. (1962). Strategy and structure: Cambridge, Mass.: MIT Press.

13. Chemweno, P., Morag, I., Sheikhalishahi, M., Pintelon, L., Muchiri, P., \& Wakiru, J. (2016). Development of a novel methodology for root cause analysis and selection of maintenance strategy for a thermal power plant: A data exploration approach. Engineering Failure Analysis, 66, 19-34.

14. Cyert, R. M., \& March, J. G. (1963). A behavioral theory of the firm. Englewood Cliffs, NJ: Prentice-Hall.

15. Desai, V. (2008). Constrained Growth: How Experience, Legitimacy, and Age Influence Risk Taking in Organizations. Organization Science, 19(4), 594-608.

16. Einstein, A., \& Infeld, L. (1938). The evolution of physics. New York: Simon and Schuster.

17. Garratt, B. (1999). The Learning Organisation 15 years on: some personal reflections. The Learning Organization, 6(5), 202-207.

18. Gharahasanlou AN, Mokhtarei A, Khodayarei A, Ataei M. Fault tree analysis of failure cause of crushing plant and mixing bed hall at Khoy cement factory in Iran. Case Studies in Engineering Failure Analysis 2014:2(1):33-38.

19. Grant, R. (1996). Toward a knowledge-based theory of the firm. Strategic Management Journal, 17(S2), 109-122.

20. Greve, H. R. (2003). Organizational learning from performance feedback: A behavioral perspective on innovation and change. Cambridge University Press.

21. Hayward, M., Rindova, V., \& Pollock, T. (2004). Believing one's own press: the causes and consequences of CEO celebrity. Strategic Management Journal, 25(7), 637-653.

22. Kim, J., \& Miner, A. (2000). Crash Test Without Dummies: A Longitudinal Study Of Interorganizational Learning From Failure Experience In The U.S. Commercial Banking Industry, 1984-1998. Academy Of Management Proceedings, 2000(1), G1G6.

23. Kim, J., \& Miner, A. (2007). Vicarious learning from the failures and near-failures of others: Evidence from the US commercial banking industry. Academy $O f$ Management Journal, 50(3), 687-714.

24. Kletz, T. A. (1993). Lessons from disaster: how organizations have no memory and accidents recur. Rugby: Institution of Chemical Engineers.

25. Kletz, T. A. (2001). Learning from accidents. Routledge. 
26. Kogut, B., \& Zander, U. (1996). What Firms Do? Coordination, Identity, and Learning. Organization Science, 7(5), 502-518.

27. Komljenovic, D., Loiselle, G., \& Kumral, M. (2017). Organization: A new focus on mine safety improvement in a complex operational and business environment. International Journal of Mining Science and Technology, 27(4), 617-625.

28. Komljenovic, D., Gaha, M., Abdul-Nour, G., Langheit, C., \& Bourgeois, M. (2016). Risks of extreme and rare events in Asset Management. Safety science, 88, 129-145.

29. Labib, Ashraf, and Harris, John, Learning how to learn from failures: the Fukushima nuclear disaster, Engineering Failure Analysis, 47 (2015) 117-128.

30. Labib, Ashraf, Learning from Failures: Decision Analysis of Major Disasters, Butterworth-Heinemann, Oxford, 450 p, 2014,.

31. Labib, A., \& Read, M. (2013). Not just rearranging the deckchairs on the Titanic: Learning from failures through Risk and Reliability Analysis. Safety Science, 51(1), 397-413.

32. Labib, A., \& Read, M. (2015). A hybrid model for learning from failures: The Hurricane Katrina disaster. Expert Systems With Applications, 42(21), 7869-7881.

33.Labib, A. W., \& Shah, J. (2001). Management decisions for a continuous improvement process in industry using the analytical hierarchy process. Work Study, 50(5), 189-194.

34. Lant, T. K. (1992). Aspiration Level Adaptation: An Empirical Exploration. Management Science, 38(5), 623-644.

35. Leveson, N. (2004). A new accident model for engineering safer systems. Safety Science, 42(4), 237-270.

36. Levinthal, D., \& March, J. (1981). A model of adaptive organizational search. Journal Of Economic Behavior \& Organization, 2(4), 307-333.

37. Louis, M., \& Sutton, R. (1991). Switching Cognitive Gears: From Habits of Mind to Active Thinking. Human Relations, 44(1), 55-76.

38. Madsen, P., \& Desai, V. (2010). Failing to Learn? The Effects of Failure and Success on Organizational Learning in the Global Orbital Launch Vehicle Industry. Academy Of Management Journal, 53(3), 451-476.

39. March, J., \& Shapira, Z. (1992). Variable risk preferences and the focus of attention. Psychological Review, 99(1), 172-183.

40. Martinez VO, Fernández MI, Nicieza CG. Failure analysis of subsidence in an effluent treatment plant in a thermosolar power plant. Engineering Failure Analysis. 2018 Sep 1;91:419-32.

41. McGrath, R. G. (1999). Falling forward: Real options reasoning and entrepreneurial failure. Academy Of Management Review, 24(1), 13-30.

42. Mesić M, Plavšić T. The contribution of failure analyses to transmission network maintenance preferentials. Engineering Failure Analysis. 2013 Dec 15;35:262-71.

43. Miles, R. H., \& Cameron, K. S. (1982). Coffin nails and corporate strategies. Prentice Hall.

44. Miner, A., Kim, J., Holzinger, I., \& Haunschild, P. (1996). Fruits of failure: Organizational failure and population-level learning. Academy Of Management Proceedings, 1996(1), 239-243.

45. Mirvis, P. H., \& Berg, D. N. (1977). Failures in organization development and change: cases and essays for learning. New York; Chichester (etc.): Wiley.

46. Morris, M., \& Moore, P. (2000). The Lessons We (Don't) Learn: Counterfactual Thinking and Organizational Accountability after a Close Call. Administrative Science Quarterly, 45(4), 737. 
47. Mulenga K, Zhao X, Xie M, Chikamba C. Investigating the root causes of major failures of critical components-With a case study of asbestos cement pipes. Engineering Failure Analysis. 2018 Feb 1;84:121-30.

48. Murugan R, Ramasamy R. Failure analysis of power transformer for effective maintenance planning in electric utilities. Engineering Failure Analysis. 2015 Sep 1;55:182-92.

49. NTSB. (1997). In-flight fire and impact with terrain: ValuJet airlines Flight 592: DC9-32, N904VJ: Everglades, near Miami, Florida: May 11, 1996. National Transportation Safety Board.

50. Peters, T. J., Waterman, R. H., \& Jones, I. (1982). In search of excellence: Lessons from America's best-run companies. New York: Harper \& Row.

51. Qi, R., Prem, K., Ng, D., Rana, M., Yun, G., \& Mannan, M. (2012). Challenges and needs for process safety in the new millennium. Process Safety And Environmental Protection, 90(2), 91-100.

52. Santayana, G. (1998). The life of reason. New York (Estados Unidos): Prometheus Books.

53. Senge, P. (2006). The fifth discipline: The art and practice of the learning organization (2nd ed.). London: Random House Business.

54. Sitkin, S. B. (1992). Learning through failure: the strategy of small losses. Research in organizational behavior, 14, 231-266.

55. Sitkin, S., \& Pablo, A. (1992).Reconceptualizing the determinants of risk behavior. Academy Of Management Review, 17(1), 9-38.

56. Stalk, G., Evans, P., \& Shulman, L. E. (1992). Competing on Capabilities: The New Rules of Corporate Strategy. Harvard Business Review, 70(2), 57-69.

57. Stephen, C, and Labib, A, (2018). A Hybrid Model for Learning from Failures, Expert Systems With Applications, 93, 212-222.

58. Taleb, N. (2005). The black swan: Why don't we learn that we don't learn. NY: Random House.

59. TSB. (2001). In-Flight Fire Leading to Collision with Water: Swissair Transport Limited McDonnell Douglas MD-11 2 September 1998. Transportation Safety Board Of Canada.

60. Turner, B. (1976). The Organizational and Interorganizational Development of Disasters. Administrative Science Quarterly, 21(3), 378.

61. Weick, K., \& Roberts, K. (1993). Collective Mind in Organizations: Heedful Interrelating on Flight Decks. Administrative Science Quarterly, 38(3), 357-381.

62. Yunusa-Kaltungo A, Kermani MM, Labib A. Investigation of critical failures using root cause analysis methods: Case study of ASH cement PLC. Engineering Failure Analysis. 2017 Mar 31;73:25-45.

63. Yuniarto, M. N., \& Labib, A. W. (2006). Fuzzy adaptive preventive maintenance in a manufacturing control system: a step towards self-maintenance. International Journal of Production Research, 44(1), 159-180. 